\title{
Lithium enhances exercise-induced glycogen breakdown and insulin-induced AKT activation to facilitate glucose uptake in rodent skeletal muscle
}

\author{
Su-Ryun Jung ${ }^{1} \cdot$ Sol-Yi Park ${ }^{2} \cdot$ Jin-Ho Koh $^{2}$ (D) $\cdot$ Jong-Yeon Kim ${ }^{2}$ \\ Received: 26 November 2020 / Revised: 15 February 2021 / Accepted: 16 February 2021 / Published online: 3 March 2021 \\ (C) The Author(s) 2021
}

\begin{abstract}
The purpose of this study was to investigate the effect of lithium on glucose disposal in a high-fat diet-induced type 2 diabetes mellitus (T2DM) and streptozotocin-induced type 1 diabetes mellitus (T1DM) animal model along with low-volume exercise and low-dose insulin. Lithium decreased body weight, fasting plasma glucose, and insulin levels when to treat with low-volume exercise training; however, there were no adaptive responses like an increase in GLUT4 content and translocation factor levels. We discovered that lithium enhanced glucose uptake by acute low-volume exercise-induced glycogen breakdown, which was facilitated by the dephosphorylation of serine 473-AKT (Ser473-AKT) and serine 9-GSK3 $\beta$. In streptozotocin-induced T1DM mice, Li/low-dose insulin facilitates glucose uptake through increase the level of exocyst complex component 7 (Exoc7) and Ser473-AKT. Thus, lithium enhances acute exercise-induced glycogen breakdown and insulin-induced AKT activation and could serve as a candidate therapeutic target to regulate glucose level of DM patients.
\end{abstract}

Keywords Lithium $\cdot$ Exercise $\cdot$ T1DM $\cdot$ Glycogen breakdown $\cdot$ GSK3 $\beta \cdot$ AKT

\section{Introduction}

Approximately 50 years ago, lithium, an alkali metal element was found to increase glucose uptake and glycogen synthesis in rat diaphragm muscle [12, 21], similar to the effects of insulin and contraction on skeletal muscle and adipose tissue; consequently, lithium chloride (Li) has become the most commonly administered medicine for mania patients $[5,8,13,21]$. $\mathrm{Li}$ is not considered an attractive molecule for the development of a clinical treatment, as its effect is significantly lower than that of insulin or muscle contraction [37], and further research is still required.

Jin-Ho Koh

jinhokoh@yu.ac.kr

Jong-Yeon Kim

jykim@ynu.ac.kr

1 College of Pharmacy, Keimyung University, Daegu, Republic of Korea

2 Department of Physiology, College of Medicine, Yeungnam University, Gyeongsan, Republic of Korea
Glucose uptake induced by muscle contraction or insulin is regulated by two different underlying mechanisms; however, both the mechanisms use glucose transporter 4 (GLUT4) for glucose uptake. Signaling due to muscle contraction and insulin mediates the translocation of GLUT4 to the plasma membrane and activates GLUT4-induced glucose uptake. A previous study indicated that Li induces GLUT4 translocation to the plasma membrane, but GLUT4 is not much activated to take up glucose into the cellular than insulin and exercise [24], and the amount is only $30-40 \%$ of the rate of glucose uptake induced by insulin or tetanic contraction. This result is due to the distinct mechanisms underlying translocation and activation of GLUT4 [15, 22]; thus, Li is known to mediate GLUT4 translocation to the plasma membrane; however, the other effects of Li on glucose uptake induced by muscle contraction and insulin remain unknown.

In addition to GLUT4 translocation, various distinct mechanistic signaling pathways induced by muscle contraction or insulin are involved in glucose uptake. Previous studies have shown that low glycogen levels induced by muscle contraction play a key role in glucose uptake, and insulin-mediated protein kinase $\mathrm{B}$ (PKB; also known as AKT) activation also induces GLUT4 translocation and stimulates glucose uptake 
[36]. Although many signaling cascades are mediated by muscle contraction or insulin induce glucose uptake, GLUT4 translocation and activation is an essential step for the uptake of glucose into the skeletal muscle. Li can strongly mediate GLUT4 translocation, even with weak activation [24], indicating that it could be a candidate or supporter to facilitate glucose uptake due to another activator, such as muscle contraction or insulin. Generally, high-fat diet (HFD)-induced insulin resistance (IR) is caused by the reduction of GLUT4 translocation through a defective insulin signaling pathway [39], and in type 1 diabetes mellitus (T1DM) patients, the translocation and activation of GLUT4 does not occur due a lack of insulin production. Since Li can only enhance GLUT4 translocation to the plasma membrane, we speculated that if a low dose of insulin or muscle contraction could be used to activate GLUT4, Li-induced GLUT4 translocation may take up glucose sufficiently in the isolated skeletal muscle and improve glucose homeostasis that is dysregulated in IR and T1DM patients who cannot actively exercise or use high-dose insulin; since Li is already used in the clinic, and its metabolic side effects are hard to find except for the contradictory results on the glomerulus $[9,28,30,31,40]$; thus, Li could serve as a promising alternative.

A previous study has only determined Li effect in vitro [24]; therefore, in the current study, we investigated the significance of Li effect on glucose disposal in a HFD-induced T2DM and streptozotocin-induced T1DM animal model along with low-volume exercise and low-dosage insulin, which were not sufficient to stimulate glucose uptake.

\section{Methods}

\section{HFD-induced T2DM rats}

Male Sprague-Dawley rats ( 8 weeks old; $n=50$ ) were fed an HFD for 8 weeks to make diet-induced obese (DIO), and 10 animals were excluded as a chow control group. After 8 weeks, rats were randomly divided for 4 groups (fat control; FC, Li; fat-lithium, Ex; fat-exercise training, LiEx; fat-Li + exercise training, $n=10$ each). Rats were provided chow (carbohydrate $67 \%$, fat $13 \%$, protein $20 \%$, Purina, USA) or HFD (carbohydrate $42.7 \%$, fat $42 \%$, protein $15.2 \%$, Purina, USA) with water ad libitum. During the course of the experiment, body weight, and food consumption were measured every 2 days. The study design was approved by the Animal Experiment Ethics Committee of Daegu Technopark BioHealth Convergence Center (BHCC-IACUC-2018-01).

Ten milligram per kilogram Li chloride (L4408, SigmaAldrich, St. Louis, MO, USA) was administered orally once a day, 5 days a week for 12 weeks. Previous studies have shown that $10 \mathrm{mg} / \mathrm{kg} \mathrm{Li}$ induces $0.3-0.7 \mathrm{mmol} / \mathrm{L}$ in blood that is recommended amount for the treatment of psychiatric diseases $[16,38,45]$. We tested toxicity and found that longterm $\mathrm{Li}$ treat did not induce toxicity in the kidney and liver of DIO rats (Fig. S1). In LiEx group, Li was gavage 1 hour before exercise training. The control group was orally administered the same amount of saline. Exercise intensity was set lower than the lactate threshold to avoid masking the Li effect due to strong exercise stimulation [43]. The exercise protocol consisted of low intensity ( $40 \% \mathrm{VO} 2 \mathrm{max}, 12 \mathrm{~m} / \mathrm{min}$, slop $0 \%$ ) walking on a treadmill (FT-200, Techman Soft) for 20 min per day, 3 days a week for 12 weeks.

After 12 weeks of treatment, rats were rested for $48 \mathrm{~h}$ to eliminate the last-bout exercise effect. The rats were fasted overnight, following which they were anesthetized with pentobarbital sodium $(5 \mathrm{mg} / 100 \mathrm{~g}$ bwt), body composition was measured using DEXA, and the tissues were removed. The extracted liver and kidney were fixed with $4 \%$ formalin solution for hematoxylin and eosin (H\&E) staining. The plantaris muscles were clamp frozen after dissection and stored at -80 ${ }^{\circ} \mathrm{C}$ until analysis. The abdominal cavity was opened to collect $5 \mathrm{ml}$ of blood from the abdominal artery, which was anticoagulated with $50 \mu \mathrm{l}$ of heparin to prevent clotting. After centrifugation $(1500 \times \mathrm{g}, 15 \mathrm{~min})$, only plasma was stored at $-80^{\circ} \mathrm{C}$.

\section{Streptozotocin-induced T1DM mice}

T1DM was induced in male C57BL6/J mice (10 weeks, $n=$ 25) by intraperitoneal injection with $50 \mathrm{mg} / \mathrm{kg}$ streptozotocin (\#S-0130, Sigma-Aldrich), because no difference in glucose metabolism between rats and mice $[1,27,41]$, and it is more efficient to make T1DM with mice rather than rats. After 2 weeks, mice with fasting blood glucose concentrations of $\geq$ $350 \mathrm{mg} / \mathrm{dL}$ were selected as the streptozotocin-induced diabetic mice [26]. After 3 days of $\mathrm{Li}$ administration, the mice were divided into the following four groups: control; CC, lithium; Li, low-dose insulin; LDI, Li + low-dose insulin; Li/ LDI, Li + low-volume exercise; Li/Low-Ex, $\mathrm{Li}+$ moderatevolume exercise; Li/Mo-Ex ( $n=5$ per group). Fasting for $6 \mathrm{~h}$, $\mathrm{Li}$ was administered orally, then $1 \mathrm{~h}$ later, insulin or exercise was treated. The insulin group was injected with $0.1 \mathrm{U} / \mathrm{kg}$ insulin (Humulin R U-100) intraperitoneally. The exercise group was subjected to treadmill walking/running at a low (12 $\mathrm{m} / \mathrm{min}$, slope $0 \%, 20 \mathrm{~min})$ or moderate $(18 \mathrm{~m} / \mathrm{min}$, slope $0 \%, 30 \mathrm{~min}$ ) volume. Immediately after treatment, the animals were anesthetized with sodium pentobarbital $(5 \mathrm{mg} / 100 \mathrm{~g}$ body weight) and plantaris muscles were removed then used to measure muscle glycogen content and the rest of them used to western blotting.

\section{Glucose transport rate in skeletal muscles}

Male Wistar rats $(\sim 125 \mathrm{~g})$ were fasted for $12 \mathrm{~h}$, then they were anesthetized with pentobarbital sodium $(5 \mathrm{mg} / 100 \mathrm{~g}$ body wt). 
Thereafter, epitrochlearis muscle was excised and incubated in Dubnoff shakers in 25-ml Erlenmeyer flasks containing $2 \mathrm{ml}$ of incubation media consisting of $0.1 \%$ radioimmunoassay grade bovine serum albumin (BSA) in Krebs-Henseleit bicarbonate buffer (KHB) [17] with sufficient mannitol to maintain constant osmolarity. Flasks were gassed with 5\% $\mathrm{CO}_{2}-95 \% \mathrm{O}_{2}$. Muscles were allowed to recover for $30 \mathrm{~min}$ after dissection at $35^{\circ} \mathrm{C}$ with $2 \mathrm{mM}$ sodium pyruvate. Muscles were preincubated with or without $10 \mathrm{mM} \mathrm{Li}$ (SigmaAldrich), insulin (Pork insulin, Eli Lily, USA), or anisomycin (Sigma-Aldrich, A9789) for $60 \mathrm{~min}\left(35^{\circ} \mathrm{C}\right)$. For insulin stimulation, three insulin concentrations were used (physiological con. $60 \mu \mathrm{U} / \mathrm{ml}$, maximum con. $2 \mathrm{~m} \mathrm{U} / \mathrm{ml}$, and low con. 20 $\mu \mathrm{U} / \mathrm{ml})[18,19]$. The muscle contraction was induced by treatment with 9 19 mM anisomycin. The concentration of $\mathrm{Li}$ was maintained at $10 \mathrm{mM}$, which is the concentration that resulted in the maximum glucose transport rate in previous studies [37]. To eliminate glucose from extracellular tissues after incubation, muscle samples were washed for 10 min with KHB containing $40 \mathrm{mM}$ mannitol at $30^{\circ} \mathrm{C}$. After washing, the samples were incubated at $30^{\circ} \mathrm{C}$ for $20 \mathrm{~min}$ (second incubation) in KHB containing $4 \mathrm{mM} 2\left[^{1,3-3} \mathrm{H}\right] \mathrm{DG}(1.5 \mu \mathrm{Ci} / \mathrm{ml}$, American Radiolabeled Chemicals) and $36 \mathrm{mM}\left[{ }^{14} \mathrm{C}\right]$ mannitol $(0.2 \mu \mathrm{Ci} /$ $\mathrm{ml}$, ICN Radiochemicals). Same stimuli as in preincubation were maintained during washing and second incubation. The samples were compress-frozen and stored at $-80^{\circ} \mathrm{C}$ until analysis. The intracellular and extracellular concentrations of ${ }^{3} \mathrm{H}$ and ${ }^{14} \mathrm{C}$ were measured with scintillation counters [20].

\section{Blood profile and muscle glycogen}

Blood glucose levels were determined using a glucose analyzer (YSI 2300, Springfield, USA), ELISA kits for determining insulin (Mercodia, Uppsala, Sweden), AST, and ALT (Cayman tech., USA) levels were purchased and used according to the manufacturers' protocols. Muscle glycogen level was estimated using a glycogen assay kit (Abcam, USA).

\section{H\&E staining}

The liver and kidney were fixed in $4 \%$ formalin solution for 2 days and cut into cross sections for observation. The vertical section was embedded with paraffin to produce paraffin blocks. This block was cut at $4 \mu \mathrm{m}$ thickness and attached on a glass slide. Samples were observed with H\&E staining, which was performed using a deparaffinization and hydration process with xylene and alcohol. A virtual file was produced from these slides using Scan scope XT (Aperio Technologies, CA92081), while the average value of the cross-sectional area of the muscle fiber was analyzed using the Image scope program (Aperio Technologies, version 10.2.2.2319).

\section{Western blotting}

The extracted plantaris muscle was homogenized using icecold RIPA buffer comprising $250 \mathrm{mM}$ sucrose, $10 \mathrm{mM}$ HEPES/ $1 \mathrm{mM}$ ethylenediaminetetraacetic acid (EDTA, $\mathrm{pH}$ 7.4), $1 \mathrm{mM}$ Pefabloc (Roche), $1 \mathrm{mM}$ EDTA, $1 \mathrm{mM} \mathrm{NaF}, 1$ $\mu \mathrm{g} / \mathrm{ml}$ aprotinin, $1 \mu \mathrm{g} / \mathrm{ml}$ leupeptin, $1 \mu \mathrm{g} / \mathrm{ml}$ pepstatin, $0.1 \mathrm{mM} \mathrm{bpV}$ (phen), and $2 \mathrm{mg} / \mathrm{ml}$ glycerophosphate. The homogenized sample was subjected to three freeze/thaw cycles and centrifuged $(700 \times g, 15 \mathrm{~min})$. After quantifying the protein concentration, the prepared sample was dissolved in Laemmli buffer, loaded onto a sodium dodecyl sulfatepolyacrylamide gel, electrophoresed, and transferred to a nitrocellulose membrane. The membrane was blocked for 60 min using 5\% non-fat dry milk and Tris-buffered saline + $0.1 \%$ Tween 10 (TBST; pH 7.5), washed with TBST, and incubated overnight at $4{ }^{\circ} \mathrm{C}$ with primary antibodies against the following: GLUT4 (Santa Cruz Bio, sc-53566), GSK3 $\beta$, phospho-GSK3 $\beta$ (Santa Cruz Bio, sc-81462, sc-373800), Exoc7(Santa Cruz Bio, sc-365825), Rab10 (Santa Cruz Bio, sc-101429), Dynamin (Santa Cruz Bio, sc-17807), phosphoAKT (Cell signaling, 4060), AKT(Cell signaling, 2920), and $\beta$-actin (abcam, ab106814). After washing with TBST, the samples were treated with the secondary antibody (anti-mouse or anti-rabbit, Santa Cruz Biotechnology, Santa Cruz, CA, USA) for $60 \mathrm{~min}$. The bands were visualized using ECL (Genekhan Scientific, St. Louis, MO, USA), and the relative intensity of the bands was assessed using SigmaGel (Jandel Scientific Corp., Erkrath, Germany).

\section{Statistical analysis}

Values are means \pm SE. The significance of the differences between groups was assessed using a one-way analysis of variance followed by post hoc comparison using the Tukey significant difference method.

\section{Results}

\section{Long-term Li and Ex training improve body composition and blood glucose level in DIO rats}

To investigate the effects of $\mathrm{Li}$ and low-volume exercise training on HFD-induced IR, rats were fed a HFD (42\% fatderived calories) or normal chow (chow) for 8 weeks. All HFD groups consumed higher kcal per day (Fig. 1a), and we found that the body weight (BW) in the FC group was the highest $(p<0.05)$ among all HFD groups ( $\mathrm{Li}, \mathrm{Ex}$, and LiEx) (Fig. 1b, c). BW in the LiEx group was significantly $(p<0.05)$ lower than that in the FC group. Li and exercise decreased BW but not significantly (Fig. 1c). The DEXA scan revealed that the lean body mass (LBM) in HFD-fed mice was significantly 

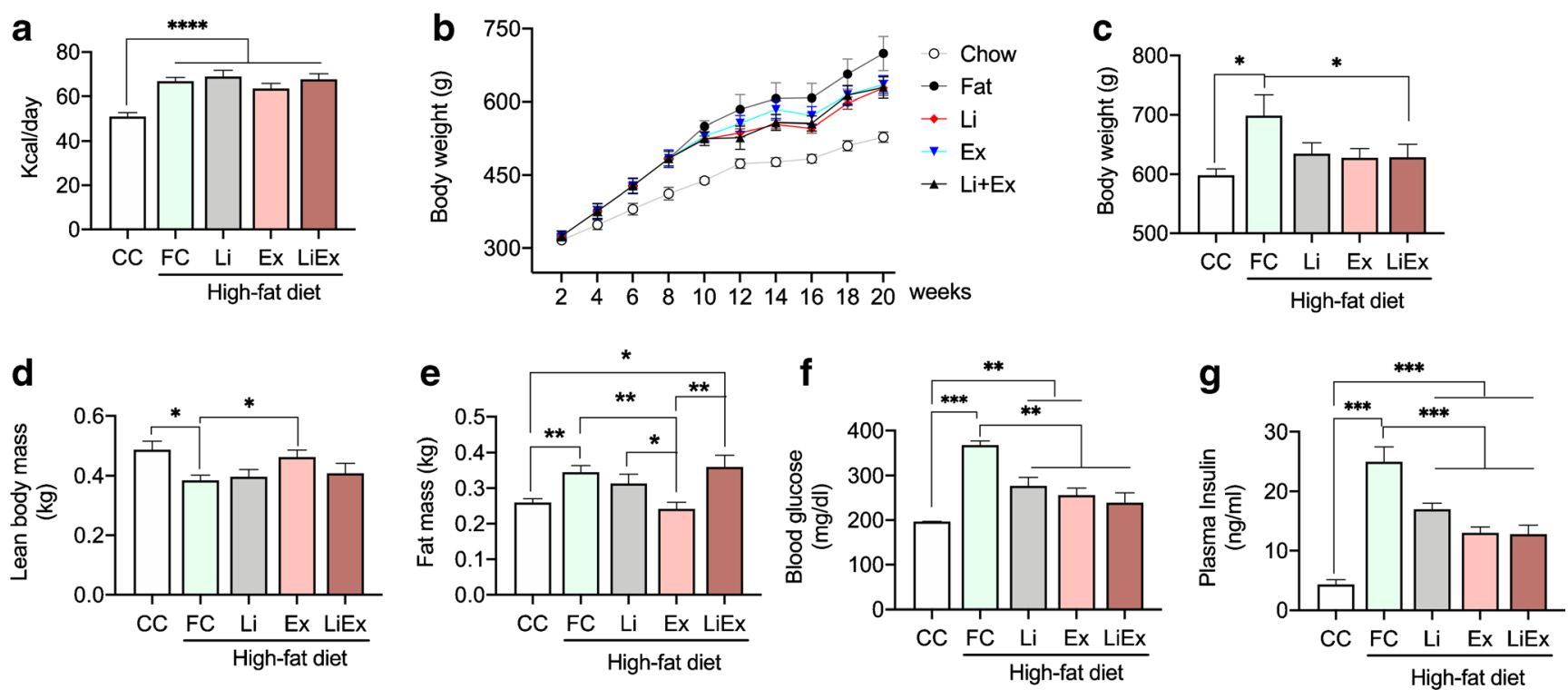

Fig. 1 Long-term $\mathrm{Li}$ and exercise training ameliorates the metabolic phenotype of diet-induced obese (DIO) rats. Rats were fed a HFD for 8 weeks followed by treatment of $\mathrm{Li}$ and/or Ex for 12 weeks. a HFD increases calorie consumption. b, c Change in body weight. d, e Body

$(p<0.05)$ lower than those fed chow, but exercise increased LBM more than that in the FC group (Fig. 1d), and HFD-fed mice showed significantly $(p<0.01)$ increased fat mass compared to those fed chow (Fig. 1e). Expectedly, the Ex group showed a decrease $(p<0.01)$ in fat mass compared to that in the $\mathrm{FC}$ group, but we found no change of fat mass in the LiEx group with FC (Fig. 1e). Interestingly, Li blocked exerciseinduced loss of fat mass of DIO mice, we and previous studies did not find the reason $[4,6,16]$. A previous in vitro study showed that $\mathrm{Li}$ increases glucose transport rate in skeletal muscles; however, the level is not as sufficient as insulin or contraction effect [24]. Therefore, we speculated that combined treatment of $\mathrm{Li}$ with low-volume exercise for 12 weeks could adaptively increase glucose disposal, as shown by the insulin or contraction effect. We found that the blood glucose levels in the HFD-fed mice were significantly higher $(p<$ 0.001) than those in the CC group, but blood glucose and insulin levels in $\mathrm{Li}, \mathrm{Ex}$, and LiEx groups were significantly $(p<0.01)$ lower than those in the FC group, despite the consumption of HFD (Fig. 1f, g). We thought the reason that fasting blood glucose and insulin levels in LiEx did not show significant effects compared to those in the Li group was because the levels were determined after $48 \mathrm{~h}$ of exercise training, and they continued to consume the HFD.

\section{Long-term Li and Ex training did not induce an adaptive increase in the levels of GLUT4 translocation factors in DIO rats}

We speculated that long-term treatment of Li with lowvolume exercise for 12 weeks would increase the levels of

composition. f, g Fasting blood glucose and insulin levels. Value are means $\pm \mathrm{SE}, * p<0.05, * * p<0.01, * * * p<0.001$. CC; chow control, FC; fat control, Li; lithium, Ex; exercise, LiEx; lithium plus exercise

various GLUT4 translocation factors; however, we found that $\mathrm{Li}$ and/or low-volume exercise for 12 weeks did not change GLUT4 content (Fig. 2a). Exocyst complex component 7 (Exoc7) [44] and RAS oncogene family (Rab10) [10] facilitate exocytosis of vesicles to the plasma membrane, the contents of these proteins were not altered by $\mathrm{Li}$, exercise, and $\mathrm{Li}$ plus low-volume exercise for 12 weeks (Fig. 2b, c). Dynamin is a GTPase for the endocytosis of GLUT4 [2] and is not changed by $\mathrm{Li}$, low-volume exercise, and Li plus lowvolume exercise for 12 weeks (Fig. 2d). Glycogen synthase kinase $3 \beta(\mathrm{GSK} 3 \beta)$ is a serine/threonine protein kinase that mediates the glycogen synthesis, and we did not observe any effect of Li and low-volume exercise (Fig. 2e). Glucose and lipid metabolism are largely dependent on mitochondria, and we found that complex II mitochondria (CII) in the lowvolume exercise group were significantly higher $(p<0.05)$ than that in the CC group (Fig. 2g); however, CI, CII, and $\mathrm{CV}$ were not changed by any of the treatments (Fig. 2f, h, i). These results indicate that either Li plus low-volume exercise did not induce adaptive response for translocation and activation of GLUT4, or it is possible that the dose of Li and exercise intensity were very low to induce an adaptive response of the skeletal muscle.

\section{Li facilitates glucose uptake induced by muscle contraction via glycogen breakdown}

Since muscle contraction induces glucose uptake in an insulin-independent manner and increases catabolism to support ATP, it consequently increases glycogen breakdown. A previous study showed that Li facilitates muscle contraction- 


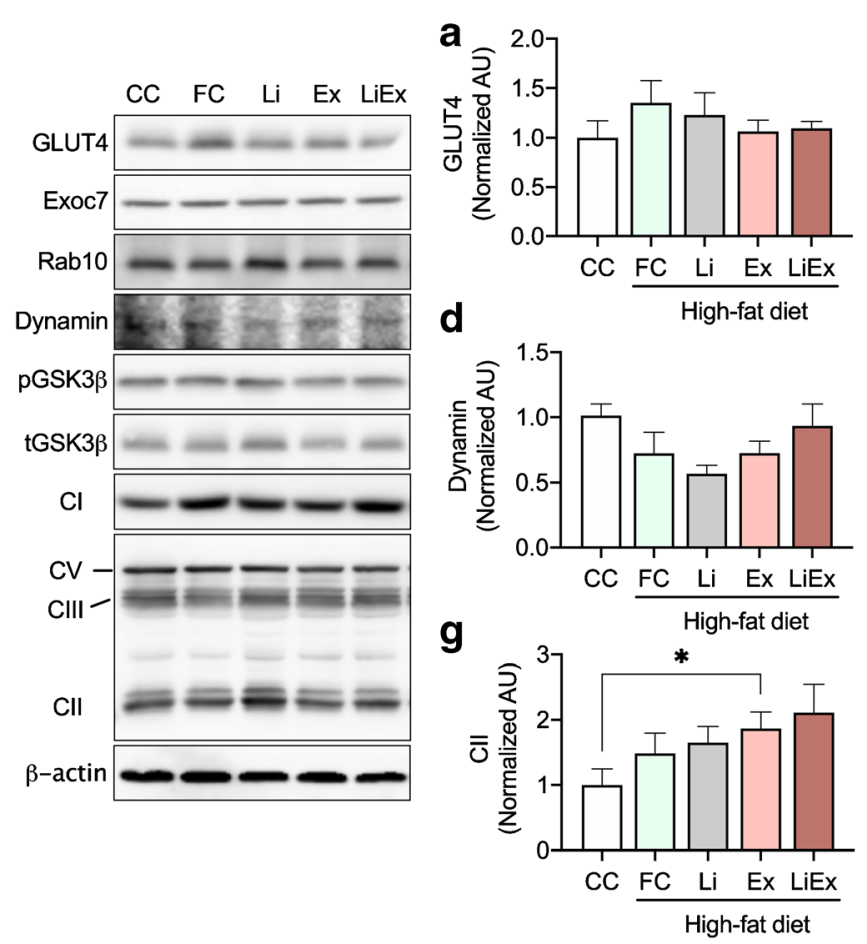

Fig. 2 Long-term $\mathrm{Li}$ and exercise training did not significantly alter protein content in skeletal muscle. Protein content was determined by western blotting in muscle of rats. a GLUT4, b Exoc7, c Rab10, d Dynamin, e phospho-GSK $3 \beta$ ratio, and $\mathbf{f}$ mitochondrial complex (C) I,

induced glucose uptake [24], and Li and insulin reportedly increases glycogen synthesis [11]; therefore, it is interesting to understand the mechanism that of whether Li can facilitate glycogen synthesis or breakdown in a contracting muscle. We speculated that $\mathrm{Li}$ was involved in muscle contraction-induced glycogen breakdown and potentially facilitated glucose uptake in an insulin-independent manner, although Li with Ext did not induce proteins related to glucose uptake in skeletal muscle $48 \mathrm{~h}$ post-exercise (Fig. 2). First, we tested whether Li could enhance muscle contraction-induced glucose uptake in vitro, using anisomycin, which mimics muscle contraction [14] and slightly increases glucose uptake; however, Li treatment with anisomycin significantly increased $(p<0.01)$ glucose uptake, although this effect was significantly lower $(p<$ 0.05 ) than that of Li treatment with insulin (Fig. 3a). We aimed to determine whether the effect of $\mathrm{Li}$ was affected by muscle contractile intensity and found that the effect of $\mathrm{Li}$ on muscle contraction-induced glucose uptake resulted in an increase depending on the muscle contraction intensity (Fig. $3 b)$. Reportedly, AKT and GSK3 $\beta$ are linked to Li effects on glucose uptake [29]; therefore, we determined the effects of Li with low-intensity ( $12 \mathrm{~m} / \mathrm{min}, \mathrm{Li} / \mathrm{Low}-\mathrm{Ex})$ for $20 \mathrm{~min}$ and moderate-intensity $(20 \mathrm{~m} / \mathrm{min}, \mathrm{Li} / \mathrm{Mo}-\mathrm{Ex})$ exercise for 40 min on AKT and GSK3 $\beta$ protein content. We found that Li with Mo-Ex significantly decreased muscle glycogen levels (Fig. 3c) and Li with Low- and Mo-Ex decreased pSer473AKT levels, indicating that muscle contraction facilitates
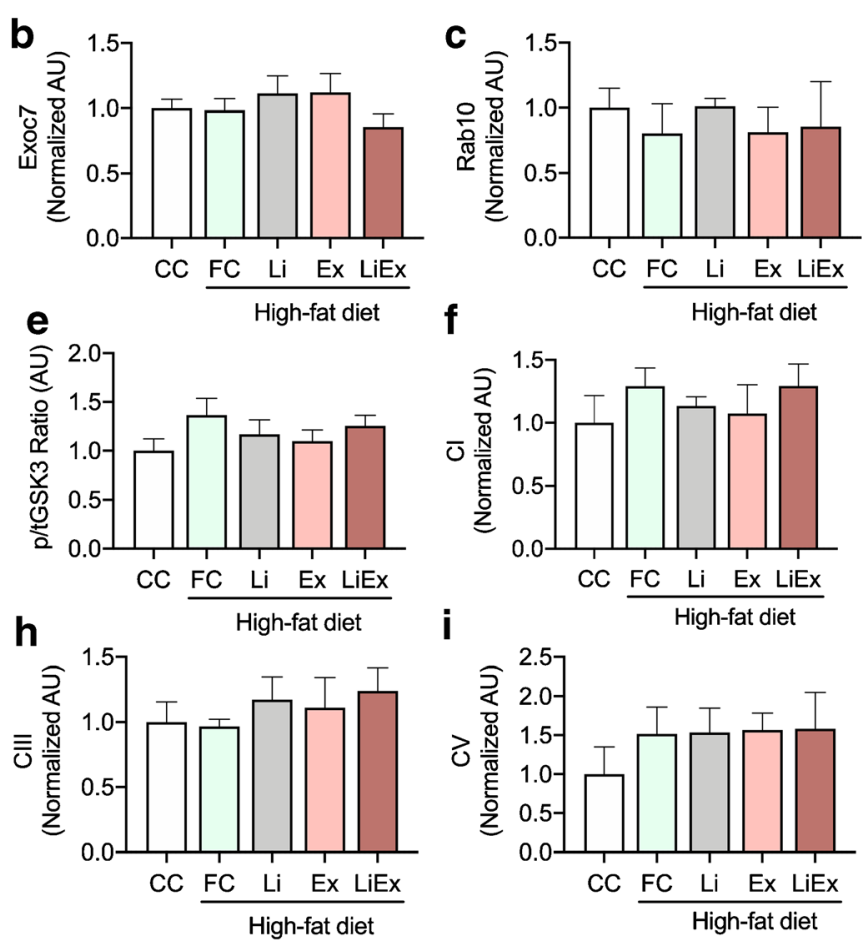

g CII, $\mathbf{h}$ CIII, $\mathbf{i}$ and CV were determined by western blotting $(n=10$ muscles per group). Values are means $\pm \mathrm{SE}, * p<0.05$. CC; chow control, FC; fat control, Li; lithium, Ex; exercise, LiEx; lithium plus exercise

catabolism (Fig. 3d). Interestingly, only Li with Mo-Ex significantly decreased the phosphorylation and total amount of serine GSK $3 \beta$, and these data also indicate that $\mathrm{Li}$ facilitates muscle contraction induced by catabolism (Fig. 3e). GSK3 $\beta$ phosphorylation in muscles that were subjected to Li and MoEx treatments was significantly lower than that in the Con $(p<$ $0.01)$ and Li/Low-Ex groups $(p<0.05)$. Interestingly, in the same group, total-GSK3 $\beta$ (tGSK3 $\beta$ ) was significantly lower $(p<0.05)$ than that in the Li, Con $(p=0.057)$, or Li/Low-Ex $(p$ $=0.052$ ) groups, whereas tGSK $3 \alpha$ in Li/Low-Ex and Li/MoEx was significantly higher than Con group. Moreover, the GSK $3 \beta$ phosphorylation ratio was computed, and the phosphorylation ratio was found to be significantly lowered in the Li with Mo-Ex group compared to that in the Con (Fig. 3e). These data indicate that Li facilitates glucose uptake and glycogen breakdown induced by muscle contraction through block phosphorylation of Ser473-AKT and GSK3 $\beta$.

\section{Li facilitates low dosage insulin-induced glucose up- take in T1DM mouse via Exoc7 and Ser473-AKT}

Since Li only exerted acute effects on glucose uptake (Fig. 3), low-volume exercise did not indicate the adaptive increase of Li-induced glucose disposal and uptake rate (Fig. 2), and thus, we speculated that Li could facilitate low dosage insulininduced glucose disposal rate in T1DM, induced by streptozotocin (STZ). We found that the low dosage insulin 


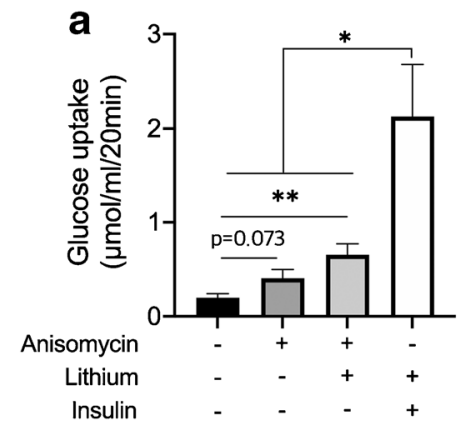

d
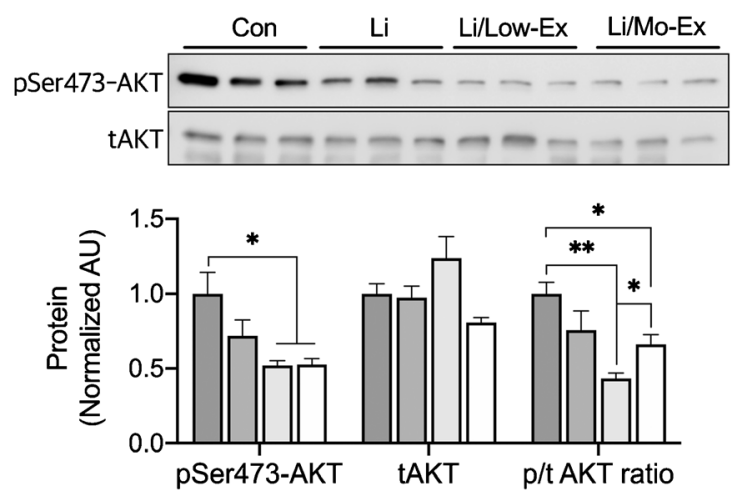

Con

Fig. 3 Li facilitates Ex or muscle contraction-induced glucose uptake. a, b Anisomycin, $\mathrm{Li}$, and insulin was treated in isolated rats muscle, and determined glucose uptake ( $n=6$ muscles per group). c-e Mice were treated with Li along with Low-Ex or Mo-Ex. c Muscle glycogen level in mice was determined immediately after exercise or Li treatment. d, e

or Li concentration used for patients with bipolar disorder did not affect fasting blood glucose levels in T1DM mice (Fig. 4a). However, Li plus low dosage insulin significantly increased $(p<0.01)$ glucose disposal in the blood of T1DM mice (Fig. 4a). The level of glucose uptake in the skeletal muscle induced by insulin was dependent on insulin concentration (Fig. 4b) and maximum insulin dosage resulted in an increase in an approximately 8 -fold glucose uptake (Fig. 4b). However, low dosage insulin only increased approximately 2fold in T1DM mouse skeletal muscle (Fig. 4b). We found that Li plus low dosage insulin additively increased glucose uptake in T1DM skeletal muscle, although Li alone could not induce glucose uptake (Fig. 4b). Treatment with low dosage insulin alone and Li plus low dosage insulin resulted in a higher increase in GSK3 $\beta$ phosphorylation ratio compared to treatment with Con or Li alone (Fig. 4c-i). We could not find any significance of dynamin induced by $\mathrm{Li}$ and/or insulin (Fig. 4h). Interestingly, acute Li consumption resulted in an approximately 5-fold increase in Exoc7 levels compared to those of the control in TA; however, low dosage insulin did not induce an increase in Exoc7 levels (Fig. 4g). Moreover, Li alone did not induce an increase in AKT phosphorylation and $\mathrm{Li}$ with
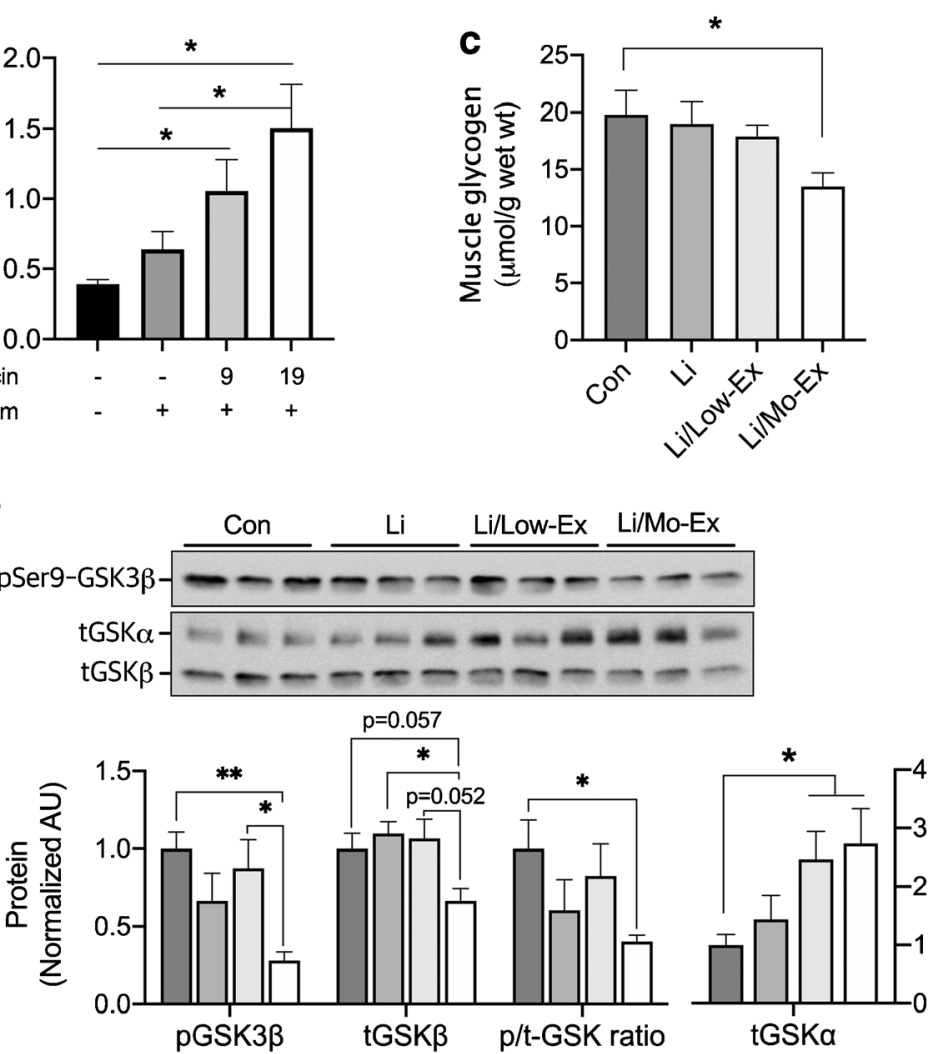

\section{Li/Low-Ex $\square$ Li/Mo-Ex}

AKT and GSK3 $\beta$ phosphorylation were determined by western blotting. d Effect of $\mathrm{Li}$ and acute exercise on AKT phosphorylation, e Effect of $\mathrm{Li}$ and acute exercise on GSK $3 \beta$ phosphorylation ( $n=5$ muscles per group). Value are means $\pm \mathrm{SE}, * p<0.05, * * p<0.01$. Li; lithium, Low-Ex; lowvolume exercise, Mo-Ex; moderate-volume exercise

insulin increased AKT activation by approximately 3.6-fold more than that by insulin (Fig. 4i). These effects contribute toward lower fasting blood glucose levels (Fig. 4a). Lowdosage insulin induced AKT phosphorylation (Fig. 4i), but it was not enough to reduce fasting glucose levels (Fig. 4a). Therefore, Li can facilitate glucose homeostasis via Exoc7induced translocation of GLUT4 and insulin-mediated AKT activation in T1DM mice.

\section{Discussion}

Although the effects of Li on the brain have been widely studied, most studies have focused on bipolar disorder and not on glucose uptake in skeletal muscle. A previous study indicated that $\mathrm{Li}$ increases glucose uptake in the skeletal muscle, although the capacity to take up glucose into muscles is lower than that of contraction and insulin stimulation [24]. Muscle is an important tissue that takes up 80\% glucose postprandial state; however, the mechanism underlying Li effect on glucose uptake in skeletal muscle has not been extensively studied and is largely unknown. Here, we studied whether exercise can activate 


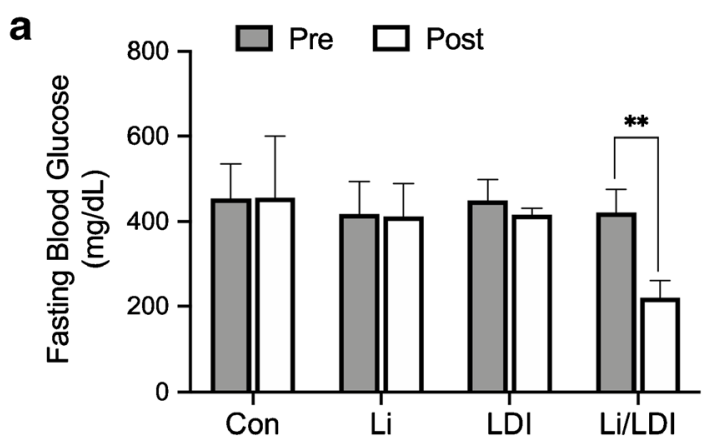

C
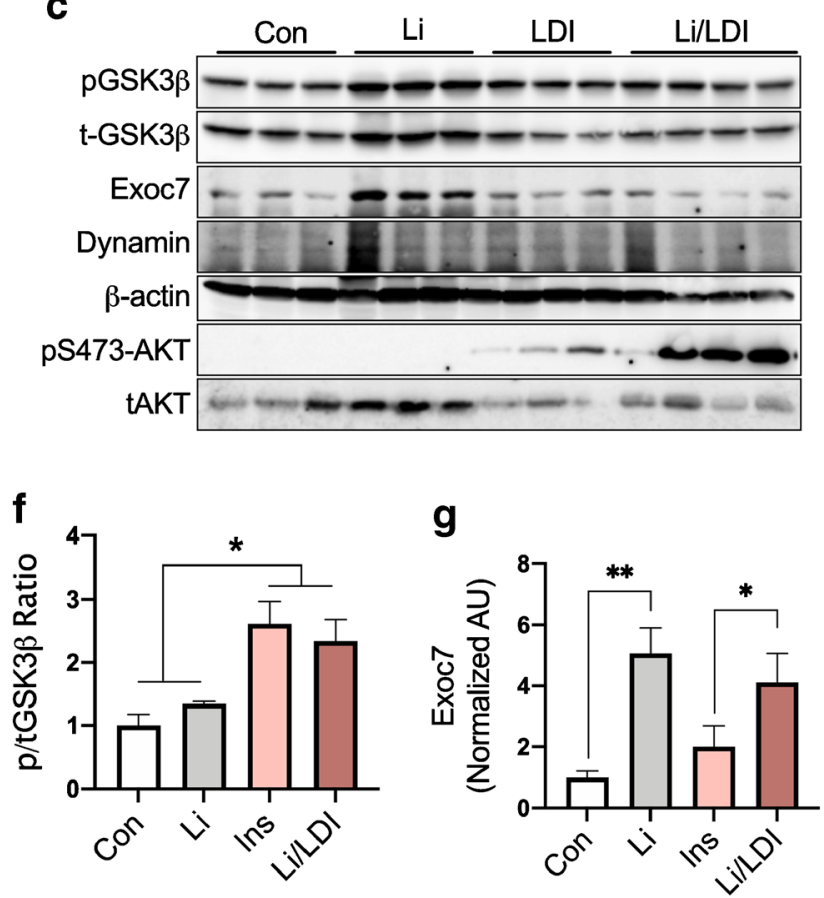

Fig. $4 \mathrm{Li}$ accelerates insulin-induced glucose uptake by enhancing AKT activation. a-i Mice were induced T1DM using STZ. a Fasting blood glucose level according to the treatment ( $n=5$ mice per group). b Muscle glucose uptake following treatment with Li or low dosage insulin $(n=5$ muscle per group). $\mathbf{c}-\mathbf{i}$ GSK $3 \beta$ phosphorylation (d), total GSK $3 \beta$ content

GLUT4 induced by Li to take up glucose into skeletal muscle in obese mice, and if low-dose insulin can facilitate Li-induced glucose disposal in T1DM mice.

IR caused by HFD in the skeletal muscle decreases the capacity of blood glucose disposal in the postprandial state and increases the incidence rate of T2DM. Muscle contraction increases glucose uptake in an insulin-independent manner; however, there are issues pertaining to obtaining the benefits of exercise in the elderly or people who cannot exercise regularly. Generally, regular exercise training with $70 \% \mathrm{VO}_{2}$ max improves insulin sensitivity, GLUT4 levels, and mitochondrial enzyme content in the skeletal muscle. We speculated that $\mathrm{Li}$ could induce the adaptive response of skeletal b

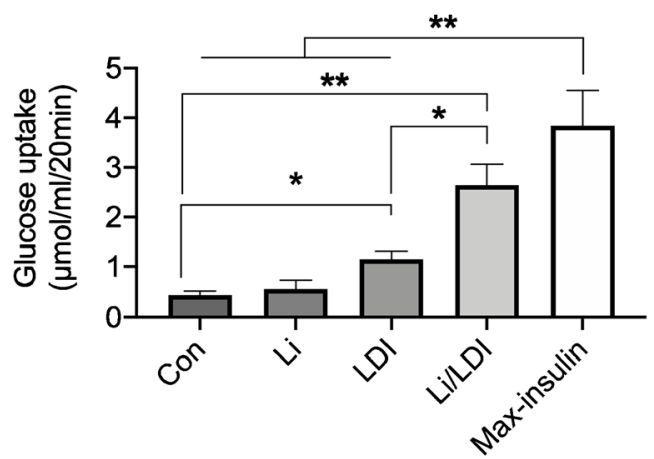

d

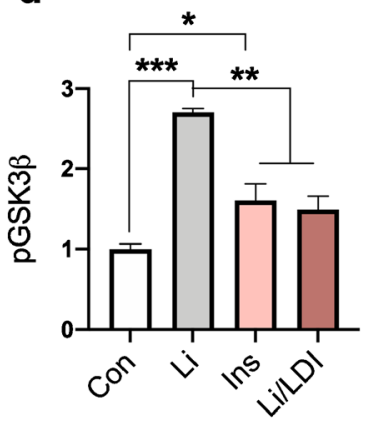

e

h

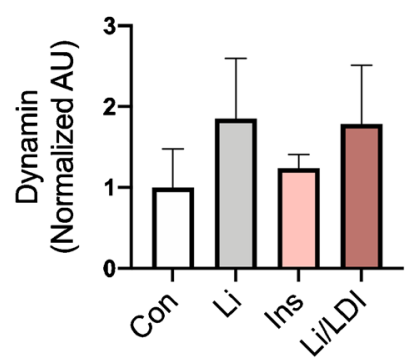

i

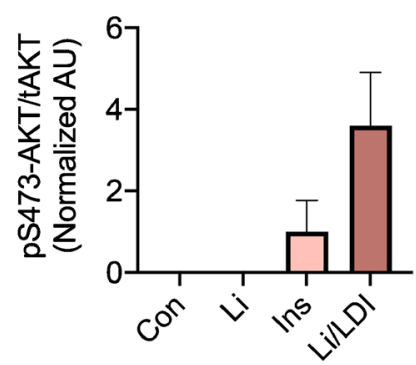

(e), ratio of phosphorylation/total GSK3 $\beta$ (f), Exoc7 level (g), dynamin content (h), and ratio of S473 phosphorylation/total AKS (i) following Li and low dosage insulin ( $n=5$ muscles per group). Value are means $\pm \mathrm{SE}$, $* p<0.05, * * p<0.01$, and ${ }^{* * *} p<0.001$. Con; control, Li; lithium, Ins; insulin, LDI; low-dose insulin

muscle, even with low-intensity exercise and duration, and this adaptive response can assist patients who require better glucose homeostasis. However, no effects of GLUT4 translocation, glucose uptake, and adaptive response induced by $\mathrm{Li}$ with Low-Ex training were found $48 \mathrm{~h}$ post-exercise. Although Li, Ex, and LiEx groups were fed an HFD, loss of body weight in the rats of these groups might reduce fasting glucose levels. We did not demonstrate insulin responsiveness in the skeletal muscle. Since it is possible that insulin sensitivity in muscle was improved by long-term $\mathrm{Li}, \mathrm{Ex}$, and $\mathrm{LiEx}$ treatment, we cannot exclude the possibility that improved insulin sensitivity induces lower fasting glucose levels. Thus, further study is warranted. 
Even though Li did not induce an adaptive response of skeletal muscle following low-volume exercise, Li enhanced muscle contraction-induced glucose uptake in a contraction intensity-dependent manner. Interestingly, Ser473-AKT and Ser9-GSK3 $\beta$ were dephosphorylated in an exercise volumedependent manner. This observation provides new insights into how Li facilitates muscle contraction-induced glucose uptake, because the dephosphorylation of Ser473-AKT and Ser9-GSK3 blocks the metabolic flow of glycogen synthesis, which can facilitate glycogen breakdown and support pyruvate for muscle contraction. Moreover, a previous study has shown that GSK3 $\beta$ is sensitive to the chelation of free $\mathrm{Mg}^{2+}$ by ATP and is gradually decreased when ATP concentrations exceed that of $\mathrm{Mg}^{2+}$ [33]. Thus, the reduction of ATP concentration by muscle contraction increases GSK3 $\beta$ activity (dephosphorylation), which decreases glycogen synthesis by glycogen synthase (GS) activation and facilitates glycogen breakdown to replenish ATP. Li did not directly affect glycogen levels in the skeletal muscle, and the reduction of Ser473AKT and Ser9-GSK3 $\beta$ phosphorylation by Li may facilitate glycogen breakdown. The rate of carbohydrate oxidation depends on exercise intensity [32, 42], and muscle contraction increases glycogen breakdown [34] to replenish pyruvate. As shown in a previous study, muscle contraction stimulates glucose uptake, and the ratio depends on glycogen breakdown based on contraction intensity [3, 25].

Interestingly, Li ingestion along with acute exercise increased $\operatorname{tGSK} 3 \alpha$, whereas it decreased tGSK $3 \beta$, the phosphorylation rate of GSK $3 \beta$ will inevitably be low in muscles with low tGSK3 $\beta$ content, and this may facilitate the inactivation of GS, which cannot carry out glycogen synthesis. Previous studies have shown that GKS $3 \beta$ inhibition improves glucose uptake [7]. Moreover, glycogen levels after muscle contraction show a positive correlation with glucose uptake level and glycogen breakdown induced by muscle contraction in skeletal muscles may improve insulin sensitivity at the resting state [23]. Therefore, Li enhances glucose uptake induced by muscle contraction by increasing GLUT4 translocation and glycogen breakdown.

T1DM patients require daily injections of insulin for life, and trials to amplify the delivery and capacity of insulin are continuously required for ensuring the health of T1DM patients [35]. Therefore, we speculated that Li could be used to support the insulin effect and demonstrated that Li with insulin resulted in an increase in glucose uptake by approximately 6-fold more than that of the control and in an increase 2.3-fold more than the low-dose insulin that mimicked lower absorption of insulin, although the effect was lower than that of the maximum insulin dosage. Moreover, low-dose insulin (or lower absorption) could not decrease fasting blood glucose levels; however, treatment of $\mathrm{Li}$ along with insulin improved the homeostasis of blood glucose in T1DM mice. Recently, Exoc7 gene deletion in adipocyte has been shown to inhibit insulin-stimulated GLUT4 exocytosis [44], and we observed in the present study that Li increased GLUT4 exocytosis via Exoc7 and glucose uptake. However, since Li alone did not increase AKT activation, it appears that just increasing Exoc7 by $\mathrm{Li}$ alone is not sufficient to take much glucose up for T1DM mice as insulin treatment. A previous study has shown that Li inhibits the internalization of GLUT4; however, unlike insulin and muscle contraction, Li cannot highly activate GLUT4 to take up glucose into the muscle [24]. Thus, Li cannot be developed as an alternative to insulin. However, we found that $\mathrm{Li}$ can be a transitional alternative candidate for T1DM patients when using low-dose insulin. Li along with low-dose insulin increases glucose uptake and Ser473AKT activation more than insulin alone and decreases glucose levels in the blood. AKT activation induces GLUT4 translocation and stimulates glucose uptake [36]. Therefore, Li enhances low-dose insulin-induced glucose uptake via GLUT4 translocation and S473-AKT activation in T1DM mouse skeletal muscle. However, Li alone did not activate Ser473-AKT; thus, the mechanisms through which Li synergistically increases AKT activation along with insulin warrant additional studies.

Taken together, the effect of Li on increasing GLUT4 translocation into the plasma membrane can enhance glucose uptake by muscle contraction-induced glycogen breakdown. Furthermore, AKT activation by insulin can activate GLUT4 translocated by Li and facilitate glucose uptake more than that by low-dose insulin in T1DM skeletal muscle. Li regulates GSK3 $\beta$ activation level according to glycogen availability in contracting or resting muscles. Thus, the elderly, people with problems in exercising regularly, or T1DM patients require a transitional alternative to remain healthy, and $\mathrm{Li}$ could serve as a candidate therapeutic target and be relatively easily developed, as $\mathrm{Li}$ is already used to treat other disorders.

Supplementary Information The online version contains supplementary material available at https://doi.org/10.1007/s00424-021-02543-0.

Authors' contributions S-RJ, J-YK, and J-HK designed the study, analysis, and data interpretation. S-RJ and S-YP conducted all the studies. JHK and J-YK drafted the manuscript. All authors contributed to the final version of the manuscript.

Funding This research was funded by the Ministry of Education of the Republic of Korea and National Research Foundation of Korea, grant number NRF-2017S1A5A2A01024319.

Data Availability The data that support the findings of this study are available from the corresponding author upon reasonable request.

Declarations The study design was approved by the Animal Experiment Ethics Committee of Daegu Technopark BioHealth Convergence Center (BHCC-IACUC-2018-01). 
Conflicts of interest No conflicts of interest, financial or otherwise, are declared by the authors.

Open Access This article is licensed under a Creative Commons Attribution 4.0 International License, which permits use, sharing, adaptation, distribution and reproduction in any medium or format, as long as you give appropriate credit to the original author(s) and the source, provide a link to the Creative Commons licence, and indicate if changes were made. The images or other third party material in this article are included in the article's Creative Commons licence, unless indicated otherwise in a credit line to the material. If material is not included in the article's Creative Commons licence and your intended use is not permitted by statutory regulation or exceeds the permitted use, you will need to obtain permission directly from the copyright holder. To view a copy of this licence, visit http://creativecommons.org/licenses/by/4.0/.

\section{References}

1. Abdelmoez AM, Sardón Puig L, Smith JAB, Gabriel BM, Savikj M, Dollet L, Chibalin AV, Krook A, Zierath JR, Pillon NJ (2020) Comparative profiling of skeletal muscle models reveals heterogeneity of transcriptome and metabolism. Am J Phys Cell Phys 318: C615-c626. https://doi.org/10.1152/ajpcell.00540.2019

2. Al-Hasani H, Hinck CS, Cushman SW (1998) Endocytosis of the glucose transporter GLUT4 is mediated by the GTPase dynamin. J Biol Chem 273:17504-17510. https://doi.org/10.1074/jbc.273.28. 17504

3. Aslesen R, Engebretsen EM, Franch J (1985) Jensen J (2001) Glucose uptake and metabolic stress in rat muscles stimulated electrically with different protocols. J Appl Physiol 91:1237-1244. https://doi.org/10.1152/jappl.2001.91.3.1237

4. Atmaca M, Kuloglu M, Tezcan E, Ustundag B (2002) Weight gain and serum leptin levels in patients on lithium treatment. Neuropsychobiology 46:67-69. https://doi.org/10.1159/ 000065414

5. Baldessarini RJ, Tondo L, Davis P, Pompili M, Goodwin FK, Hennen J (2006) Decreased risk of suicides and attempts during long-term lithium treatment: a meta-analytic review. Bipolar Disord 8:625-639. https://doi.org/10.1111/j.1399-5618.2006.00344.x

6. Baptista T, Lacruz A, de Mendoza S, Guillén MM, Burguera JL, de Burguera M, Hernández L (2000) Endocrine effects of lithium carbonate in healthy premenopausal women: relationship with body weight regulation. Prog Neuro-Psychopharmacol Biol Psychiatry 24:1-16. https://doi.org/10.1016/s0278-5846(99)00085-8

7. Barillas R, Friehs I, Cao-Danh H, Martinez JF, del Nido PJ (2007) Inhibition of glycogen synthase kinase-3beta improves tolerance to ischemia in hypertrophied hearts. Ann Thorac Surg 84:126-133. https://doi.org/10.1016/j.athoracsur.2007.02.015

8. Bhattacharya G (1964) INFLUENCE OF LI+ ON GLUCOSE METABOLISM IN RATS AND RABBITS. Biochim Biophys Acta 93:644-646. https://doi.org/10.1016/0304-4165(64)90347-2

9. Bichet DG (2006) Lithium, cyclic AMP signaling, A-kinase anchoring proteins, and aquaporin-2. J Am Soc Nephrol 17:920922. https://doi.org/10.1681/asn.2006020135

10. Bruno J, Brumfield A, Chaudhary N, Iaea D, McGraw TE (2016) SEC16A is a RAB10 effector required for insulin-stimulated GLUT4 trafficking in adipocytes. J Cell Biol 214:61-76. https:// doi.org/10.1083/jcb.201509052

11. Choi WS, Sung CK (2000) Effects of lithium and insulin on glycogen synthesis in L6 myocytes: additive effects on inactivation of glycogen synthase kinase-3. Biochim Biophys Acta 1475:225-230. https://doi.org/10.1016/s0304-4165(00)00068-4
12. Clausen $\mathrm{T}$ (1968) The relationship between the transport of glucose and cations across cell membranes in isolated tissues. Biochim Biophys Acta 150:66-72. https://doi.org/10.1016/0005-2736(68) 90009-6

13. Freeman MP, Freeman SA (2006) Lithium: clinical considerations in internal medicine. Am J Med 119:478-481. https://doi.org/10. 1016/j.amjmed.2005.11.003

14. Geiger PC, Wright DC, Han DH, Holloszy JO (2005) Activation of p38 MAP kinase enhances sensitivity of muscle glucose transport to insulin. Am J Physiol Endocrinol Metab 288:E782-E788. https:// doi.org/10.1152/ajpendo.00477.2004

15. Goodyear LJ, Kahn BB (1998) Exercise, glucose transport, and insulin sensitivity. Annu Rev Med 49:235-261. https://doi.org/10. 1146/annurev.med.49.1.235

16. Grandjean EM, Aubry JM (2009) Lithium: updated human knowledge using an evidence-based approach: part III: clinical safety. CNS Drugs 23:397-418. https://doi.org/10.2165/00023210200923050-00004

17. Han DH, Hancock CR, Jung SR, Higashida K, Kim SH, Holloszy JO (2011) Deficiency of the mitochondrial electron transport chain in muscle does not cause insulin resistance. PLoS One 6:e19739. https://doi.org/10.1371/journal.pone.0019739

18. Han DH, Nolte LA, Ju JS, Coleman T, Holloszy JO, Semenkovich CF (2004) UCP-mediated energy depletion in skeletal muscle increases glucose transport despite lipid accumulation and mitochondrial dysfunction. Am J Physiol Endocrinol Metab 286:E347E353. https://doi.org/10.1152/ajpendo.00434.2003

19. Hancock CR, Han DH, Chen M, Terada S, Yasuda T, Wright DC, Holloszy JO (2008) High-fat diets cause insulin resistance despite an increase in muscle mitochondria. Proc Natl Acad Sci U S A 105: 7815-7820. https://doi.org/10.1073/pnas.0802057105

20. Hansen PA, Wang W, Marshall BA, Holloszy JO, Mueckler M (1998) Dissociation of GLUT4 translocation and insulinstimulated glucose transport in transgenic mice overexpressing GLUT1 in skeletal muscle. J Biol Chem 273:18173-18179. https://doi.org/10.1074/jbc.273.29.18173

21. Haugaard ES, Mickel RA, Haugaard N (1974) Actions of lithium ions and insulin on glucose utilization, glycogen synthesis and glycogen synthase in the isolated rat diaphragm. Biochem Pharmacol 23:1675-1685. https://doi.org/10.1016/ 0006-2952(74)90394-3

22. Hayashi T, Wojtaszewski JF, Goodyear LJ (1997) Exercise regulation of glucose transport in skeletal muscle. Am J Phys 273:E1039E1051. https://doi.org/10.1152/ajpendo.1997.273.6.E1039

23. Jensen J, Rustad PI, Kolnes AJ, Lai YC (2011) The role of skeletal muscle glycogen breakdown for regulation of insulin sensitivity by exercise. Front Physiol 2:112. https://doi.org/10.3389/fphys.2011. 00112

24. Jung S, Koh J, Kim S, Kim K (2017) Effect of Lithium on the Mechanism of Glucose Transport in Skeletal Muscles. J Nutr Sci Vitaminol (Tokyo) 63:365-371. https://doi.org/10.3177/jnsv.63.365

25. Lai YC, Zarrinpashneh E (1985) Jensen J (2010) Additive effect of contraction and insulin on glucose uptake and glycogen synthase in muscle with different glycogen contents. J Appl Physiol 108:11061115. https://doi.org/10.1152/japplphysiol.00401.2009

26. Maekawa S, Katagiri S, Takeuchi Y, Komazaki R, Ohtsu A, Udagawa S, Izumi Y (2017) Bone metabolic microarray analysis of ligature-induced periodontitis in streptozotocin-induced diabetic mice. J Periodontal Res 52:233-245. https://doi.org/10.1111/jre. 12387

27. Magnone M, Emionite L, Guida L, Vigliarolo T, Sturla L, Spinelli S, Buschiazzo A, Marini C, Sambuceti G, De Flora A, Orengo AM, Cossu V, Ferrando S, Barbieri O, Zocchi E (2020) Insulinindependent stimulation of skeletal muscle glucose uptake by low-dose abscisic acid via AMPK activation. Sci Rep 10:1454. https://doi.org/10.1038/s41598-020-58206-0 
28. McKnight RF, Adida M, Budge K, Stockton S, Goodwin GM, Geddes JR (2012) Lithium toxicity profile: a systematic review and meta-analysis. Lancet 379:721-728. https://doi.org/10.1016/ s0140-6736(11)61516-x

29. Nguyen T, Fan T, George SR, Perreault ML (2017) Disparate Effects of Lithium and a GSK-3 Inhibitor on Neuronal Oscillatory Activity in Prefrontal Cortex and Hippocampus. Front Aging Neurosci 9:434. https://doi.org/10.3389/fnagi.2017.00434

30. Presne C, Fakhouri F, Noël LH, Stengel B, Even C, Kreis H, Mignon F, Grünfeld JP (2003) Lithium-induced nephropathy: Rate of progression and prognostic factors. Kidney Int 64:585592. https://doi.org/10.1046/j.1523-1755.2003.00096.x

31. Robben JH, Knoers NV, Deen PM (2006) Cell biological aspects of the vasopressin type-2 receptor and aquaporin 2 water channel in nephrogenic diabetes insipidus. Am J Physiol Ren Physiol 291: F257-F270. https://doi.org/10.1152/ajprenal.00491.2005

32. Romijn JA, Coyle EF, Sidossis LS, Gastaldelli A, Horowitz JF, Endert E, Wolfe RR (1993) Regulation of endogenous fat and carbohydrate metabolism in relation to exercise intensity and duration. Am J Phys 265:E380-E391. https://doi.org/10.1152/ajpendo.1993. 265.3.E380

33. Ryves WJ, Harwood AJ (2001) Lithium inhibits glycogen synthase kinase- 3 by competition for magnesium. Biochem Biophys Res Commun 280:720-725. https://doi.org/10.1006/ bbrc. 2000.4169

34. Saltin B, Karlsson J (1971) Muscle glycogen utilization during work of different intensities. Muscle metabolism during exercise. Springer, In, pp 289-299

35. Shah RB, Patel M, Maahs DM, Shah VN (2016) Insulin delivery methods: Past, present and future. Int J Pharm Investig 6:1-9. https://doi.org/10.4103/2230-973x.176456

36. Summers SA, Garza LA, Zhou H, Birnbaum MJ (1998) Regulation of insulin-stimulated glucose transporter GLUT4 translocation and Akt kinase activity by ceramide. Mol Cell Biol 18:5457-5464. https://doi.org/10.1128/mcb.18.9.5457

37. Tabata I, Schluter J, Gulve EA, Holloszy JO (1994) Lithium increases susceptibility of muscle glucose transport to stimulation by various agents. Diabetes 43:903-907. https://doi.org/10.2337/diab. 43.7.903
38. Tondo L, Alda M, Bauer M, Bergink V, Grof P, Hajek T, Lewitka U, Licht RW, Manchia M, Müller-Oerlinghausen B, Nielsen RE, Selo M, Simhandl C, Baldessarini RJ (2019) Clinical use of lithium salts: guide for users and prescribers. Int J Bipolar Disord 7:16. https://doi.org/10.1186/s40345-019-0151-2

39. Tremblay F, Lavigne C, Jacques H, Marette A (2001) Defective insulin-induced GLUT4 translocation in skeletal muscle of high fatfed rats is associated with alterations in both Akt/protein kinase B and atypical protein kinase C (zeta/lambda) activities. Diabetes 50: 1901-1910. https://doi.org/10.2337/diabetes.50.8.1901

40. Trepiccione F, Christensen BM (2010) Lithium-induced nephrogenic diabetes insipidus: new clinical and experimental findings. J Nephrol 23(Suppl 16):S43-S48

41. Ueda-Wakagi M, Nagayasu H, Yamashita Y, Ashida AH (2019) Green Tea Ameliorates Hyperglycemia by Promoting the Translocation of Glucose Transporter 4 in the Skeletal Muscle of Diabetic Rodents. Int J Mol Sci 20. https://doi.org/10.3390/ ijms20102436

42. van Loon LJ, Greenhaff PL, Constantin-Teodosiu D, Saris WH, Wagenmakers AJ (2001) The effects of increasing exercise intensity on muscle fuel utilisation in humans. J Physiol 536:295-304. https://doi.org/10.1111/j.1469-7793.2001.00295.x

43. Wang N, Liu Y, Ma Y, Wen D (2017) High-intensity interval versus moderate-intensity continuous training: Superior metabolic benefits in diet-induced obesity mice. Life Sci 191:122-131. https://doi.org/10.1016/j.lfs.2017.08.023

44. Wang S, Crisman L, Miller J, Datta I, Gulbranson DR, Tian Y, Yin Q, Yu H, Shen J (2019) Inducible Exoc7/Exo70 knockout reveals a critical role of the exocyst in insulin-regulated GLUT4 exocytosis. J Biol Chem 294:19988-19996. https://doi.org/10.1074/jbc.RA119. 010821

45. Wong RK, Boedeker B, Hickey TM, Wilkinson DS, Johnson LF (1984) Lithium chloride: protective and antisecretory properties in rats. Gastroenterology 87:362-371

Publisher's note Springer Nature remains neutral with regard to jurisdictional claims in published maps and institutional affiliations. 